\title{
Temporal Changes of CT Findings between Non-emergency and Emergency Patients with COVID-19 Pneumonia: A Multi-centered, Retrospective, Longitudinal Study
}

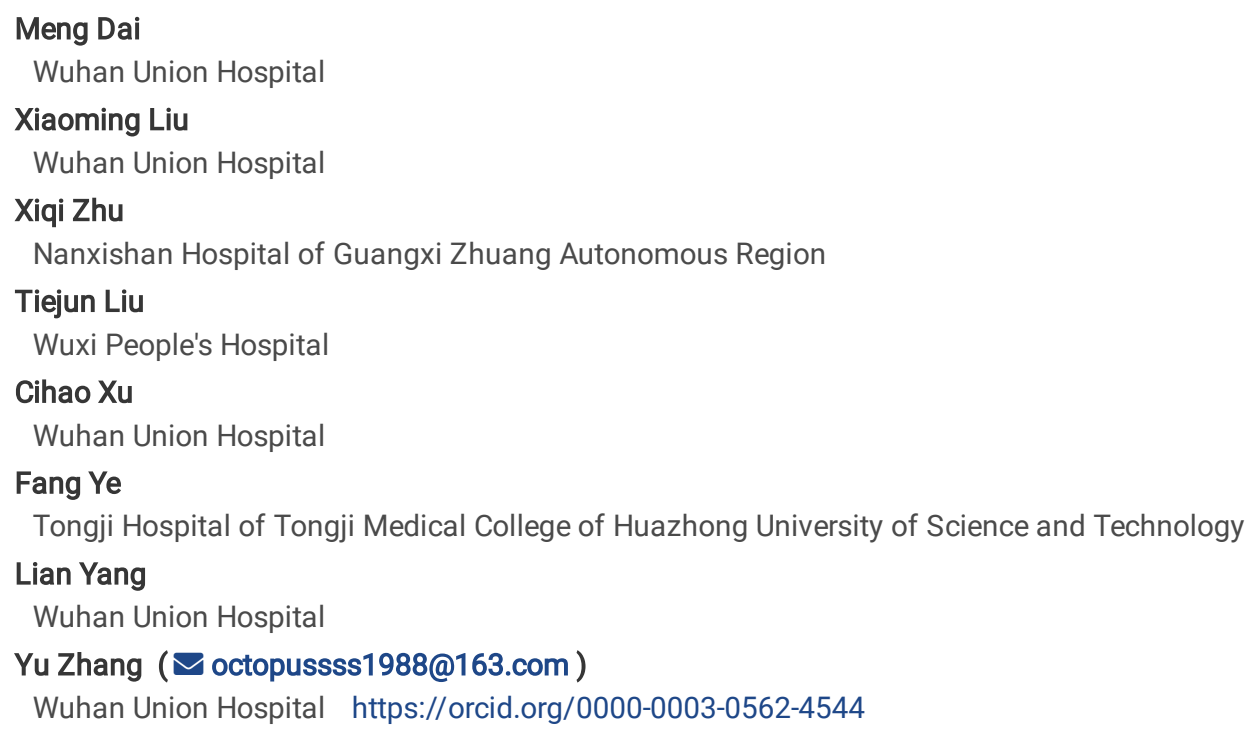




\section{Abstract}

Objective: To analyze the differences between clinical evaluation and the detailed imaging features in the time course of lung changes in diverse clinical types.

Methods: 73 patients with COVID-19 pneumonia were retrospectively collected from three institutions in China. Radiographic features, CT score were analyzed and compared between non-emergency group (mild- and common-type) and emergency group (severe- and fatal-type).

Results: In non-emergency group, the disease slowly aggravated within the first two weeks, peaked during the 2 nd week (median superimposed involvement CT score: 9.5), while in emergency group, the disease peaked in the 2nd week rapidly, and the superimposed involvement CT score(median: 20) was higher than that in non-emergency group. Both two groups began to decline in the 4th week, and persistence of high levels. In emergency group, the residual lung lesions were mostly reticular (median single reticular CT score: 10) and consolidation (median single consolidation CT score:7). By contrast, most residual lung lesions in non-emergency group were GGO (median single GGO CT score: 7) and reticular (median single reticular CT score: 4). In both non-emergency and emergency groups, GGO pattern was dominant in the first week, and the proportion in emergency group was higher [20 (65\%) and (18 (72\%), respectively], the consolidation pattern peaked in the second week, which were 9 (32\%) and 19 (73\%), respectively, reticular pattern became dominant in and after 4 weeks (both over $40 \%)$.

Conclusion: The disease in non-emergency and emergency group peaks in the second week. In the non-emergency group, the residual lesions are dominated by GGO and reticular, while those in the emergency group are mainly reticular and consolidation. The transiently CT manifestations of emergency and non-emergency follow certain patterns at different time points of the disease course.

\section{Background}

Since late December 2019, an outbreak of Coronavirus disease-19 (COVID-19) occurred in Wuhan, Hubei Province of China (1-6). Over the past few days, infections have been identified all around the world. On July 14th, 2020, the global number of confirmed cases with COVID-19 surpassed $12,964,809$, and 201 countries and territories were affected(7). On February 11th, a novel coronavirus was identified by the Chinese Center for Disease Control and Prevention (CDC) from the Chinese patients with pneumonia (2), which was named the severe acute respiratory syndrome coronavirus 2 (SARS-CoV-2) by WHO (8), which formed a clade within the subgenus sarbecovirus, Orthocoronavirinae subfamily(2).

Patients with SARS-CoV-2 infections typically present with fever, cough and dyspnea $(5,6)$. Most patients with COVID-19 have mild symptoms, whereas a few of them develop severe pneumonia, pulmonary edema, acute respiratory distress syndrome (ARDS), or multiple organ failure (MOF), and even die, just similar to those with severe acute respiratory syndrome (SARS) and Middle East respiratory syndrome (MERS)(4, 9, 10).

Chest CT examination plays an important role in the diagnosis and management of COVID-19 pneumonia (11-16). There are also reports indicating that patients with highly suspected SARS-CoV-2 infection have negative results in the initial real time reverse transcription-polymerase chainreaction (RT-PCR), but positive findings on CT images(17-19).

Previous studies $(20,21)$ have enumerated imaging features of the four clinical types (including mild, common, severe, and critical). However, the detailed imaging features, together with the differences in the course of lung changes across the diverse clinical types, have not been well investigated for COVID-19 pneumonia yet.

Therefore, this paper aimed to analyze the differences between clinical evaluation and the detailed imaging features in the time course of lung changes between non-emergency and emergency

\section{Methods}

Our study protocol was approved by the Institutional Review Board (IRB). Informed consent was waived for this retrospective study that evaluated the de-identified data and involved no potential risk to patients.

\section{Patients}

Our study protocol was approved by the Institutional Review Board (IRB). Informed consent was waived for this retrospective study that evaluated the de-identified data and involved no potential risk to patients.

This multi-center, retrospective and observational study was conducted at the designated hospitals to treat patients with COVID-19 pneumonia, including Jianghan Shelter Hospital (Wuhan, China), Guilin Nan-xi-shan Hospital (Guangxi, China), Liuzhou People's Hospital (Guangxi, China), The medical records of 73 patients with laboratory-confirmed COVID-19 infections were retrospectively collected from February 5 th, 2020 to March 8 th, 2020.The diagnosis of COVID-19 infection was confirmed according to the following methods: isolation of SARS CoV-2, or at least two positive results of real-time RT-PCR assays for SARS-CoV-2, or the detection of a genetic sequence matched with SARS-CoV-2. The severity of COVID-19 infection was defined according to the Chinese Management Guideline for COVID-19(version 6.0)(22) In this study, a total of 73 patients, including 
30 females and 43 males, with age ranging from 26 to 85 (mean, $51 \pm 13$ ) years, were enrolled. Thereafter, patients were divided into four groups according to the disease severity, including mild-, common-, severe-, and fatal-type. Additionally, the treatment regimens varied depending on the disease type, so the patients were re-grouped to non-emergency (mild- and common-type) and emergency (severe- and fatal-type) groups. Among these enrolled patients, 47 (mean age, $49 \pm 12$ years) were recruited into the non-emergency group, while 26 (mean age, $55 \pm 15$ years) were enrolled in the emergency group. Some researchers (X.L., Y.Z., M.D.) noted that the related clinical parameters included laboratory findings, date of symptom onset, indications for the scans, and presence of complications (such as pneumomediastinum, pneumothorax, and superimposed infections).

Moreover, CT scans were categorized according to the time duration between the date of symptom onset and the dates of obtaining CT images at 1 , $2,3,4$, and over 4 weeks after symptom onset.

The discharge criteria were as follows, absence of fever for at least 3 days, substantial improvement in both lungs upon chest CT, clinical remission of respiratory symptoms, and two negative results in throat-swab tests for SARS-CoV-2 RNA obtained at an interval of at least $24 \mathrm{~h}$.

\section{CT Protocol}

All thorax CT scans were performed using commercial multi-detector CT scanners at the single inspiratory phase (uCT550, Shanghai United Imaging Healthcare, Shanghai, China; Aquilion 16-slice, TOSHIBA Medical Systems; Tochigi, Japan; NeuViz 64in, Shengyang Neusoft medical system, Hunan, China; Somatom Definition AS, Siemens, Nurnberg,Germany; Brilliance 64, Phillips Medical System, Eindhoven, the Netherlands). To acquire CT images, the tube voltage was fixed at $120 \mathrm{kVp}$, the pitch was 1.075 , and the collimator widths were $64 \times 0.6 \mathrm{~mm}, 128 \times 0.6 \mathrm{~mm}, 64 \times 0.6 \mathrm{~mm}$, and 40 $\times 0.55 \mathrm{~mm}$. CT images were reconstructed based on the raw data with a matrix size of $512 \times 512$ as the axial images (thickness, $1.5 \mathrm{~mm}$ or $2 \mathrm{~mm}$; increment, $1.5 \mathrm{~mm}$ or $2 \mathrm{~mm}$ ) in the transverse slice direction. The images were taken at lung (window width, 1,000- 1,500 HU; window level, - 700 $\mathrm{HU}$ ) and mediastinal (window width, $350 \mathrm{HU}$; window level, 35-40 HU) settings.

\section{Chest CT Evaluation}

CT images of 73 were evaluated by three fellowship-trained cardiothoracic radiologists (M.D., Y.Z. with 7 and 5 years of experience in interpreting chest CT findings, respectively) using the institutional digital database system (Vue PACS, version 11.3.5.8902, Carestream Health, Canada). All Digital Imaging and Communications in Medicine (DICOM) images were interpreted from CT studies without access to clinical and laboratory findings. All images were reviewed by the radiologists independently, and the final decisions were reached by discussion and consensus. All chest CT images evaluated(16, 23-26) are shown in Table 1.

Table 1

CT imaging features of patients with COVID-19

\begin{tabular}{|c|c|}
\hline СT Characteristics & Definition \\
\hline Lobe involvement & Categorized as right upper lobe, right middle lobe, right lower lobe, left upper lobe and left lower lobe involvement \\
\hline \multirow{2}{*}{$\begin{array}{l}\text { The lung segment } \\
\text { involved }\end{array}$} & Each segment of the lung was reviewed for GGO, Consolidation and Reticular, respectively \\
\hline & Categorized as unilateral or bilateral lung involvement \\
\hline Lesion location & Central, lesion located in the interior two-thirds of the lung; Peripheral, in the outer one-third of the lung; \\
\hline \multirow{2}{*}{$\begin{array}{l}\text { Extent of lesion } \\
\text { involvement }\end{array}$} & Both central and peripheral \\
\hline & Categorized as focal, multifocal, diffuse \\
\hline $\begin{array}{l}\text { Predominantly } \\
\text { distribution of } \\
\text { opacities }\end{array}$ & $\begin{array}{l}\text { Septal/subpleural, involving mainly the subperipheral one-third of the lung; Perbronchovasular, surrounding mainly the } \\
\text { peribronchovascular bundle. Random, without predilection for subpleural or peribronchovascular regions }\end{array}$ \\
\hline $\begin{array}{l}\text { Predominantly CT } \\
\text { pattern }\end{array}$ & $\begin{array}{l}\text { GGO pattern, an area of hazy increased lung opacity, within which margins of pulmonary vessels may be indistinct; } \\
\text { Consolidation pattern, a homogeneous increase in pulmonary parenchymal attenuation that obscures the margins of } \\
\text { vessels and airway walls; Reticular pattern,a descniptive term usually associated with interstitial lung diseases; Mixed } \\
\text { pattern,combination of GGO,consolidation, and reticulation }\end{array}$ \\
\hline $\begin{array}{l}\text { Interlobular septal } \\
\text { thickening }\end{array}$ & Including smooth interlobular septal thickening or irregular interlobular septal thickening \\
\hline Pleural effusion & Fluid in the pleural cavity \\
\hline Lymphadenopathy & arbitrary thresholds for the upper limit of normal of $1 \mathrm{~cm}$ in short-axis diameter for mediastinal nodes \\
\hline
\end{tabular}

A semi-quantitative analysis was used to quantify disease severity.(11, 27). For each lung lobe, a score that represented the extent of lung superimposed involvement (GGO, consolidation and reticular) was visually rated from 0 to 5 , as shown below, 0 , none; $1,<5 \%$ lobe involvement; 2 , 5-25\% lobe involvement; 3, 26-49\% lobe involvement; 4, 50-75\% lobe involvement; and 5, > 75\% lobe involvement. 
The single GGO, single consolidation, and single reticular CT score were evaluated, respectively, according to the same criteria described above. The total CT score ranged from $0 \sim 25$, which represented none to maximum lung involvement and each of the three findings scored at each thin-section CT examination.

\section{Statistical Analysis}

Illness day 0 was defined as the day of initial symptom onset. The median values of superimposed involvement CT score, single GGO CT score, single consolidation CT score and single reticular CT score and number of zones involved as a function of time were plotted. The temporal changes of main CT patterns, subtypes of ground-glass opacity, and the distribution of lung abnormalities were also analyzed. Kruskal Wallis rank-sum test was used for the difference between the median values of CT lung quantification in different period, and Chi-square test was applied to compare the frequency of CT patterns in different period. P-value of $<0.05$ was considered to be statistically significant. Statistical analyses were performed using R software (version 3.6.2, the R Foundation for Statistical Computing, Vienna, Austria).

\section{Results}

\section{Comparison of Basic Clinical Characteristics}

Altogether 73 patients were enrolled in this study. Among them, 47 were non-emergency (including 32 males and 15 females, with the age of $49 \pm$ 12 years), and 26 were emergency (including 11 males and 15 females, with the age of $55 \pm 15$ years) cases. Among the non-emergency cases, $68 \%$ were male patients, while $58 \%$ of emergency cases were female. As for the concurrent underlying disease (Table 2 ), $56 \%$ of patients had different underlying diseases, among which hypertension (29\%) and fatty liver (18\%) were dominant. In the emergency group, $61 \%$ of patients had nonpulmonary underlying diseases, while $41 \%$ of non-emergency patients had non-pulmonary underlying diseases. Fever ( $86 \%$ ), cough (62\%), and dyspnea (56\%) were the most common symptoms; over $70 \%$ of emergency cases had cough and dyspnea, while diarrhea (26\%) and anorexia (58\%) were more commonly seen in non-emergency patients. In the emergency group, the time from positive nucleic acid RT-PCR to the initial symptom onset was earlier than that in the non-emergency group, and the time of two successive negative nucleic acid tests was later than that in the nonemergency group. In addition, the imaging peak time from the initial symptom onset in non-emergency and emergency groups occurred in the second week (Table 2), and the time was close. 
Table 2

Clinical characteristics of patients with COVID-19

\begin{tabular}{|c|c|c|c|}
\hline & $\begin{array}{l}\text { All patient } \\
(n=73)\end{array}$ & $\begin{array}{l}\text { Non-emergency } \\
(n=47)\end{array}$ & Emergency $(n=26)$ \\
\hline \multicolumn{4}{|l|}{ Characteristics } \\
\hline Age, year & $51 \pm 13$ & $49 \pm 12$ & $55 \pm 15$ \\
\hline \multicolumn{4}{|l|}{ Sex } \\
\hline Men & $43(59 \%)$ & $32(68 \%)$ & $11(42 \%)$ \\
\hline Women & $30(41 \%)$ & $15(32 \%)$ & $15(58 \%)$ \\
\hline Any comorbidity & $41(56 \%)$ & $24(51 \%)$ & $17(65 \%)$ \\
\hline Diabetes & $8(11 \%)$ & $4(9 \%)$ & $4(15 \%)$ \\
\hline Hypertension & $21(29 \%)$ & $13(28 \%)$ & $8(31 \%)$ \\
\hline Cardiovascular disease & $7(10 \%)$ & $5(11 \%)$ & $2(8 \%)$ \\
\hline COPD & $3(4 \%)$ & $2(4 \%)$ & $1(4 \%)$ \\
\hline Tuberculosis & $3(4 \%)$ & $3(6 \%)$ & 0 \\
\hline Fatty liver & $13(18 \%)$ & $11(23 \%)$ & $2(8 \%)$ \\
\hline Hepatitis B & 10(14\%) & $6(13 \%)$ & $4(15 \%)$ \\
\hline \multicolumn{4}{|l|}{ Signs and symptoms } \\
\hline Fever & $64(86 \%)$ & $41(87 \%)$ & $23(88 \%)$ \\
\hline \multicolumn{4}{|l|}{ Highest temperature, ${ }^{\circ} \mathrm{C}$} \\
\hline$凶 37.3$ & $9(12 \%)$ & $6(13 \%)$ & $3(12 \%)$ \\
\hline $37.3-38$ & $13(18 \%)$ & $10(21 \%)$ & $3(12 \%)$ \\
\hline $38.1-39$ & $38(52 \%)$ & $23(49 \%)$ & $15(58 \%)$ \\
\hline \39 & 13(18\%) & $8(17 \%)$ & $5(19 \%)$ \\
\hline Cough & $45(62 \%)$ & $26(55 \%)$ & 19(73\%) \\
\hline Chest tightness & $41(56 \%)$ & $21(45 \%)$ & $20(77 \%)$ \\
\hline Diarrhea & $13(18 \%)$ & $12(26 \%)$ & $1(4 \%)$ \\
\hline Anorexia & $28(38 \%)$ & $27(58 \%)$ & $1(4 \%)$ \\
\hline Headache & $5(7 \%)$ & $1(2 \%)$ & $4(15 \%)$ \\
\hline Myalgia and fatigue & $27(37 \%)$ & $18(38 \%)$ & $9(35 \%)$ \\
\hline Time of Hospitalized & $24(12)$ & $21(8)$ & $32(10)$ \\
\hline Time from symptoms to image peak & $11(3)$ & $12(10)$ & $11(3)$ \\
\hline Time from symptoms to PCR positive & $7(7)$ & $9(7)$ & $3(4)$ \\
\hline Time from symptoms to PCR negative & $33(11)$ & $29(12)$ & $37(10)$ \\
\hline
\end{tabular}

\section{Comparison of Basic CT Imaging Involvement}

In the non-emergency group, bilateral lower lobe involvements were more common, and involvement of the middle lobe of the right lung accounted for the lowest proportion among the 5 lung lobes. In the emergency group, over $95 \%$ of patients had simultaneous involvement of 5 lung lobes within the initial 4 weeks of the disease course, and this proportion was also as high as over $90 \%$ after 4 weeks. 
In the non-emergency group, over $85 \%$ of patients had the tendency of bilateral lung involvements, while in the emergency group, obvious bilateral lung involvements were observed within 1 week after disease onset.

In non-emergency and emergency groups, the disease site and scope were dominated by both central and peripheral and diffuse types, without predilection for subpleural or peribronchovascular regions. (Table 3) 
Table 3

CT feature of patients with COVID-19.

\begin{tabular}{|c|c|c|c|c|c|c|c|c|c|c|}
\hline & \multicolumn{5}{|c|}{ Non-emergency } & \multicolumn{5}{|l|}{ Emergency } \\
\hline & $\begin{array}{l}1 \text { week } \\
(n=31)\end{array}$ & $\begin{array}{l}\text { 2week } \\
(n=28)\end{array}$ & $\begin{array}{l}\text { 3week } \\
(n=25)\end{array}$ & $\begin{array}{l}\text { 4week } \\
(n=23)\end{array}$ & $\begin{array}{l}\otimes 4 \text { week } \\
(n=17)\end{array}$ & $\begin{array}{l}1 \text { week } \\
(n=25)\end{array}$ & $\begin{array}{l}2 \text { week } \\
(n=26)\end{array}$ & $\begin{array}{l}\text { 3week } \\
(n=21)\end{array}$ & $\begin{array}{l}\text { 4week } \\
(n=22)\end{array}$ & $\begin{array}{l}\otimes 4 \text { week } \\
(n=13)\end{array}$ \\
\hline \multicolumn{11}{|l|}{ Lobe } \\
\hline Left upper lobe & $23(74 \%)$ & $20(71 \%)$ & $23(92 \%)$ & $18(78 \%)$ & $15(88 \%)$ & $24(96 \%)$ & $25(96 \%)$ & $21(100 \%)$ & $22(100 \%)$ & $12(92 \%)$ \\
\hline Left lower lobe & $26(84 \%)$ & $26(93 \%)$ & $24(96 \%)$ & $21(91 \%)$ & $17(100 \%)$ & $24(96 \%)$ & $26(100 \%)$ & $21(100 \%)$ & $22(100 \%)$ & $13(100 \%)$ \\
\hline Right upper lobe & $20(66 \%)$ & $20(71 \%)$ & $22(88 \%)$ & $19(83 \%)$ & $15(88 \%)$ & $24(96 \%)$ & $26(100 \%)$ & $21(100 \%)$ & $22(100 \%)$ & $13(100 \%)$ \\
\hline Right middle lobe & $15(48 \%)$ & $18(64 \%)$ & $19(76 \%)$ & $14(61 \%)$ & $11(65 \%)$ & $25(100 \%)$ & $26(100 \%)$ & $21(100 \%)$ & $22(100 \%)$ & $13(100 \%)$ \\
\hline Right lower lobe & $29(94 \%)$ & $25(89 \%)$ & $24(96 \%)$ & $21(91 \%)$ & $17(100 \%)$ & $24(96 \%)$ & $26(100 \%)$ & $21(100 \%)$ & $22(100 \%)$ & $13(100 \%)$ \\
\hline \multicolumn{11}{|l|}{ Lung involvement } \\
\hline Unilateral & $4(13 \%)$ & $4(14 \%)$ & $1(4 \%)$ & $3(13 \%)$ & 0 & 0 & 0 & 0 & 0 & 0 \\
\hline Bilateral & $27(87 \%)$ & $24(86 \%)$ & $24(96 \%)$ & $20(87 \%)$ & $17(100 \%)$ & $25(100 \%)$ & $26(100 \%)$ & $21(100 \%)$ & $22(100 \%)$ & $13(100 \%)$ \\
\hline \multicolumn{11}{|l|}{ Lesions location } \\
\hline Central & 0 & 0 & 0 & 0 & 0 & $2(8 \%)$ & 0 & 0 & 0 & 0 \\
\hline Peripheral & $10(32 \%)$ & $7(25 \%)$ & $6(24 \%)$ & $5(22 \%)$ & $3(18 \%)$ & $4(16 \%)$ & $1(4 \%)$ & 0 & $1(5 \%)$ & $1(8 \%)$ \\
\hline $\begin{array}{l}\text { Both central and } \\
\text { peripheral }\end{array}$ & $21(68 \%)$ & $21(75 \%)$ & $19(76 \%)$ & $17(74 \%)$ & $14(82 \%)$ & $19(76 \%)$ & $25(96 \%)$ & $21(100 \%)$ & $21(95 \%)$ & $12(92 \%)$ \\
\hline \multicolumn{11}{|c|}{ Extent of lesion involvement } \\
\hline Focal & $3(10 \%)$ & $2(7 \%)$ & $1(4 \%)$ & $3(13 \%)$ & $1(6 \%)$ & 0 & 0 & 0 & 0 & 0 \\
\hline Multifocal & $12(39 \%)$ & $4(14 \%)$ & $2(8 \%)$ & $2(9 \%)$ & $3(18 \%)$ & $11(44 \%)$ & $2(8 \%)$ & $4(19 \%)$ & $5(23 \%)$ & $5(38 \%)$ \\
\hline Diffuse & $16(52 \%)$ & $22(79 \%)$ & $22(88 \%)$ & $18(78 \%)$ & $13(76 \%)$ & $14(56 \%)$ & $24(86 \%)$ & $17(81 \%)$ & $17(77 \%)$ & $8(62 \%)$ \\
\hline \multicolumn{11}{|c|}{ Predominantly distribution of opacities } \\
\hline Septal/subpleural & $9(29 \%)$ & $7(25 \%)$ & $6(24 \%)$ & $6(26 \%)$ & $3(18 \%)$ & $2(8 \%)$ & $1(4 \%)$ & $1(5 \%)$ & 0 & 0 \\
\hline Perbronchovasular & $8(26 \%)$ & $2(7 \%)$ & 0 & $2(9 \%)$ & $3(18 \%)$ & $10(40 \%)$ & $6(23 \%)$ & $3(14 \%)$ & $10(45 \%)$ & $4(31 \%)$ \\
\hline Random & $14(45 \%)$ & $19(68 \%)$ & $19(76 \%)$ & $15(65 \%)$ & $11(65 \%)$ & $13(52 \%)$ & $18(69 \%)$ & $17(81 \%)$ & $12(55 \%)$ & $9(69 \%)$ \\
\hline \multicolumn{11}{|c|}{ Predominantly CT pattern } \\
\hline $\begin{array}{l}\text { Ground glass } \\
\text { opacity pattern }\end{array}$ & $20(65 \%)$ & $8(29 \%)$ & $6(24 \%)$ & $7(30 \%)$ & $4(24 \%)$ & $18(72 \%)$ & $4(15 \%)$ & 0 & 0 & $2(15 \%)$ \\
\hline $\begin{array}{l}\text { Consolidation } \\
\text { pattern }\end{array}$ & $6(19 \%)$ & $9(32 \%)$ & $5(20 \%)$ & $1(4 \%)$ & 0 & $3(12 \%)$ & $19(73 \%)$ & $7(33 \%)$ & $4(18 \%)$ & 0 \\
\hline Reticular pattern & 0 & $2(7 \%)$ & $5(20 \%)$ & $12(53 \%)$ & $12(70 \%)$ & 0 & 0 & $3(14 \%)$ & $11(50 \%)$ & $6(46 \%)$ \\
\hline Mixed pattern & $5(16 \%)$ & $9(32 \%)$ & $9(36 \%)$ & $3(13 \%)$ & $1(6 \%)$ & $4(16 \%)$ & $3(12 \%)$ & $11(53 \%)$ & $7(32 \%)$ & $5(39 \%)$ \\
\hline \multicolumn{11}{|l|}{ Ground glass opacity } \\
\hline $\begin{array}{l}\text { Number of } \\
\text { involved segments }\end{array}$ & $5(7)$ & $5(9)$ & $8(7)$ & $6(8)$ & $7(12)$ & $15(4)$ & $7(6)$ & $5(4)$ & $3(4)$ & $2(4)$ \\
\hline $\begin{array}{l}\text { Single ground } \\
\text { glass opacities CT } \\
\text { score }\end{array}$ & $5(5)$ & $5.5(7.3)$ & $6.5(6)$ & $7(7)$ & $7(5)$ & $12(7)$ & $6(3)$ & $3(2)$ & $1(1)$ & $1(2)$ \\
\hline \multicolumn{11}{|l|}{ Consolidation } \\
\hline $\begin{array}{l}\text { Number of } \\
\text { involved segments }\end{array}$ & $2(6)$ & $4(5)$ & $1(7)$ & $0(1)$ & $0(0)$ & $4(4)$ & $9(6)$ & $7(5)$ & $5(6)$ & $6(5)$ \\
\hline
\end{tabular}

Number of involved segments, single ground glass opacities CT score, single consolidation CT score, single reticular CT score and superimposed involvement CT score were presented as median (IQR), the other data are presented as $\mathrm{n}(\mathrm{n} / \mathrm{N} \%)$, where $\mathrm{N}$ is the total number of patients with available data. 


\begin{tabular}{|c|c|c|c|c|c|c|c|c|c|c|}
\hline \multirow[b]{2}{*}{$\begin{array}{l}\text { Single } \\
\text { consolidation CT } \\
\text { score }\end{array}$} & \multicolumn{5}{|c|}{ Non-emergency } & \multicolumn{5}{|c|}{ Emergency } \\
\hline & $2(5)$ & $3.5(6)$ & $2(5.8)$ & $0(1)$ & $0(0)$ & $3(2)$ & $13.5(6.8)$ & $9(4)$ & $8(5)$ & $7(6)$ \\
\hline \multicolumn{11}{|l|}{ Reticular } \\
\hline $\begin{array}{l}\text { Number of } \\
\text { involved segments }\end{array}$ & $0(0)$ & $0(1)$ & $1(5)$ & $3(7)$ & $4(7)$ & 0 & $1(5)$ & $5(6)$ & $7(8)$ & $8(5)$ \\
\hline $\begin{array}{l}\text { Single reticular CT } \\
\text { score }\end{array}$ & $0(0)$ & $0(1.3)$ & $1.5(5)$ & $2(6)$ & $4(4)$ & $0(0)$ & $0(2)$ & $8(2)$ & $9(2.8)$ & $10(2)$ \\
\hline $\begin{array}{l}\text { Superimposed } \\
\text { involvement CT } \\
\text { score }\end{array}$ & $7(7.5)$ & $9.5(8.5)$ & $10(6)$ & $9(7)$ & $9(11)$ & $15(7)$ & $20(2.8)$ & $20(4)$ & $19(6.5)$ & $18(2)$ \\
\hline $\begin{array}{l}\text { Pure ground-glass } \\
\text { opacities }\end{array}$ & $22(71 \%)$ & $13(46 \%)$ & $10(40 \%)$ & $8(35 \%)$ & $7(41 \%)$ & $11(44 \%)$ & $2(8 \%)$ & $1(5 \%)$ & $1(5 \%)$ & $1(8 \%)$ \\
\hline $\begin{array}{l}\text { Ground-glass } \\
\text { opacities plus } \\
\text { Interlobular septal } \\
\text { thickening }\end{array}$ & $8(26 \%)$ & $4(14 \%)$ & $1(4 \%)$ & 0 & 0 & $21(84 \%)$ & $14(54 \%)$ & $4(19 \%)$ & 0 & 0 \\
\hline $\begin{array}{l}\text { Ground-glass } \\
\text { opacities plus } \\
\text { irregular line }\end{array}$ & $12(39 \%)$ & $13(46 \%)$ & $16(64 \%)$ & $12(52 \%)$ & $8(47 \%)$ & $3(12 \%)$ & $6(23 \%)$ & $18(86 \%)$ & $8(36 \%)$ & $4(31 \%)$ \\
\hline Reticular & $1(3 \%)$ & $4(14 \%)$ & $11(44 \%)$ & $12(52 \%)$ & $11(65 \%)$ & $0(0 \%)$ & $1(4 \%)$ & $13(62 \%)$ & $22(100 \%)$ & 12(92\%) \\
\hline Fibrotic changes & $3(10 \%)$ & $12(43 \%)$ & $16(64 \%)$ & $13(57 \%)$ & $14(82 \%)$ & $1(4 \%)$ & $2(8 \%)$ & $12(57 \%)$ & $21(95 \%)$ & $13(100 \%)$ \\
\hline Consolidation & $18(58 \%)$ & $17(61 \%)$ & $14(56 \%)$ & $5(22 \%)$ & $4(24 \%)$ & $4(16 \%)$ & 19(73\%) & $17(81 \%)$ & $20(91 \%)$ & $8(62 \%)$ \\
\hline $\begin{array}{l}\text { Traction } \\
\text { bronchiectasis }\end{array}$ & 0 & 0 & $1(4 \%)$ & $2(9 \%)$ & $2(12 \%)$ & $2(8 \%)$ & $4(15 \%)$ & $3(14 \%)$ & $9(41 \%)$ & $7(54 \%)$ \\
\hline Pleural effusion & 0 & 0 & 0 & 0 & 0 & $2(8 \%)$ & $4(15 \%)$ & $3(14 \%)$ & $1(5 \%)$ & 0 \\
\hline
\end{tabular}

\section{Comparison of Thin-Section CT Scores}

In the non-emergency group, the disease slowly aggravated within the first two weeks, the median superimposed involvement CT score increased from 7 (range, 0-18) points in the first week to the peak of 9.5 (range, 1-24) points to the second week, it began to decline in the 4th week and reduced to 9 (range, 2-19) points after 4 weeks (Fig. 1a). Such a result revealed the presence of residual lesion at the late stage of the disease. Differences in the superimposed involvement CT score in the non-emergency group at different time periods were not statistically significant $(P=0.435)$. In the emergency group, the disease peaked in the 2 nd week rapidly, and the median superimposed involvement $C T$ score was as high as 20 (range, 8-25) points. In the 3rd week, the median superimposed involvement CT score in emergency group maintained at the peak value (20; range, 7-25 points). It began to decline slowly in the 4 th week and was 18 (range,12-22) points after 4 weeks. Differences in the superimposed involvement CT score in the emergency group at different time periods were statistically significant $(P=0.000)$. The median superimposed involvement CT score in the emergency group in each time point was higher than that in the non-emergency group $(P=0.000)$, suggesting the presence of obviously greater residual lung lesions in emergency than in non-emergency.

In the non-emergency group, the single GGO CT scores showed no statistical difference at different time period of disease $(P=0.204)$; in emergency group, the median single GGO CT score gradually decreased from the 12 (range, 4-19) points in the first week to the 1 (range, 0-4) point after 4 weeks (Fig. 1b), and difference in single GGO CT score among different time period was statistically significant $(P=0.000)$. In non-emergency and emergency group, the median single consolidation CT scores peaked in the second week, which was 4 and 14 points in non-emergency and emergency groups, respectively; and the lowest scores in the above two groups were obtained after 4 weeks, which were 0 and 7 , respectively (Fig. 1C.). Differences in the single consolidation CT score at different time period were statistically significant in the non-emergency group $(P=0.000)$, the median single consolidation CT score in the emergency group in each time point was higher than that in the non-emergency group ( $P$ $=0.000$ ). In non-emergency and emergency group, the median single reticular CT score was lower in the first two weeks, which gradually elevated from the second week, and peaked after 4 weeks ( 4 and 8 points for non-emergency and emergency groups, respectively) (Fig. 1d.). Differences in single reticular CT score at different time period in non-emergency $(P=0.000)$ and emergency $(P=0.000)$ were statistically significant, and the score in the emergency group was remarkably higher than that in the non-emergency group after 3 weeks. In the emergency group, the residual lung 
lesions were mostly reticular and consolidation, with reticular being more common. By contrast, most residual lung lesions in the non-emergency group were GGO and reticular, with GGO being more common.

\section{Comparison of Predominantly CT Patterns}

In both non-emergency and emergency groups, the GGO pattern was dominant in the first week, and the proportion in the emergency group was higher [20 (65\%) and (18 (72\%), respectively]. Thereafter, the GGO pattern began to decrease substantially, and almost no GGO pattern was observed in the middle and late stages of the disease course in the emergency group. In non-emergency and emergency groups, the consolidation pattern peaked in the second week, which were 9 (32\%) and 19 (73\%), respectively, and the proportion in the emergency group was apparently higher than that in the non-emergency group. Later, the consolidation pattern gradually decreased, and it was almost not seen in both groups after 4 weeks. In non-emergency and emergency groups, reticular pattern began in the second and third weeks, respectively, which notably increased after that, and became dominant in and after 4 weeks (both over $40 \%$, Fig. 2a,3,4).

\section{Comparison of Positive CT Features}

In the first week of disease onset in the non-emergency group, the pure GGO accounted for the highest proportion (22/31, 71\%), while in the emergency group, GGO plus interlobular septal thickening was the most common $(21 / 25,84 \%)$. In non-emergency and emergency groups, the most common imaging sign in the second week of disease was consolidation, which were $17(61 \%)$ and 19 (73\%), respectively, in both groups. In the emergency group, pure GGO, GGO plus interlobular septal thickening, and GGO plus irregular line accounted for a low proportion after 3 weeks, which was consistent with the markedly decreased single GGO CT score in the emergency group after 3 weeks. In the non-emergency group, reticular and fibrotic changes, and GGO plus irregular line were the most common in and after 4 weeks of the disease, while reticular and fibrotic changes and consolidation were the most common in the emergency group (Table 3, Fig. 2b,4).

\section{Discussion}

This paper systemically described the longitudinal research on non-emergency and emergency COVID-19 pneumonia, and the detailed comparisons between them. According to our results, both non-emergency and emergency groups reached the disease peak in the second week after initial symptom onset, and the score in the emergency group was higher. With the disease development, the imaging scores in non-emergency and emergency groups declined to various degrees, but they did not decrease to 0 point, revealing the presence of massive residual lesion after the negative conversion of the nucleic acid test. In the non-emergency group, the residual lesions were dominated by GGO and reticular, while those in the emergency group were mainly consolidation and reticular. Moreover, we also compared the different development patterns of non-emergency and emergency at different longitudinal time periods. To our knowledge, this is the first comparative description of a longitudinal thin-section CT series between non-emergency and emergency patients with clinically and laboratory-confirmed COVID-19.

In our non-emergency patient cohort, the disease peak was reached in the second week, which conformed to previous literature (11, 12, 23). At the same time, we also discovered that many lung lobes were involved in the third week, and the maximal diffuse proportion was attained at this moment (88\%). The emergency patient cohort revealed that the disease peaked in the second week, which rapidly progressed from the first week to the second week, and it was similar to the development pattern of SARS(23). The peaks in non-emergency and emergency groups gradually declined thereafter, but they still maintained at the high levels, which were consistent with previous literature $(12,23)$. In addition, the SARS follow-up literature also suggested that, among the 24 patients discharged, 20 were detected with a residual lung lesion on chest X-ray films.

We also carried out a semi-quantitative analysis on different lesions, and examined the development trend with time in longitudinal research, which was not mentioned in previous studies. In the non-emergency group, GGO remained in a high proportion, and the residual lesions at the late disease course were mostly GGO and reticular. According to previous research, GGO is reversible to a large extent $(23,28)$. Therefore, we speculated that the occurrence of GGO at the late stage was the sign of disease improvement in the course of non-emergency, which was consistent with the conclusions drawn from SARS. On the contrary, we discovered that the proportion of GGO was low at the middle and late stages in the course of emergency, and the residual lesions were mainly reticular and consolidation. The SARS follow-up research(29) indicates that the elderly patients in an intensive care unit (ICU) are more likely to develop irreversible pulmonary fibrosis. In our study, the median age of the emergency group was higher than that of the non-emergency group. Consequently, we speculated that the emergency patients were more likely to develop irreversible pulmonary fibrosis, but this should be further verified in future studies.

In the first week after initial symptom onset, the CT imaging types of non-emergency and emergency patients were dominated by GGO pattern, among them, the non-emergency patients mainly showed the GGO pattern, while the emergency patients mainly exhibited GGO accompanying with an interlobular septal thickening. Typically, such imaging finding of GGO with or without interlobular septal thickening was similar to the previously reported CT finding of viral pneumonia induced by SARS and MERS(23, 30-32). However, almost no GGO pattern was seen in the middle and late stages of disease in emergency patients. These studies also suggested that pure GGO, GGO plus interlobular septal thickening, and GGO plus irregular line accounted for less than $5 \%$ among all positive CT imaging signs, which might be related to the more severe disease in emergency 
group. In non-emergency and emergency groups, the consolidation pattern peaked in the second week, which were 9 (32\%) and 19 (73\%), respectively, and the proportion in the emergency group was apparently higher than that in the non-emergency group. At the same time, the disease in the emergency group peaked in the second week, revealing that the occurrence of disease peak was strictly related to the consolidation pattern on lung CT images. At the late stage of the disease, the reticular pattern was dominant in non-emergency and emergency groups, among all positive imaging signs, reticular and fibrotic changes took up the highest proportion. The occurrence of reticular is usually accompanying with bronchiectasis and structural distortion(23), revealing the possibility of further developing into pulmonary fibrosis (29).

Certain limitations should also be noted in this study. First of all, death cases are lacking in this study, and the comparative analysis with death cases allows for better disease prediction. Additionally, a longer follow-up observation should be further investigated.

\section{Conclusion}

The disease in non-emergency and emergency group peaks in the second week, and there are massive residual lesions at the late stage of the disease. In the non-emergency group, the residual lesions are dominated by GGO and reticular, while those in the emergency group are mainly reticular and consolidation. The transiently distinct CT manifestations of emergency and non-emergency follow certain patterns at different time points of the disease course, which is related to the disease severity, progression, and recovery.

\section{Abbreviations}

COVID-19: Corona virus disease 2019; SARS-CoV-2: Severe acute respiratory syndrome coronavirus 2; SARS: Severe acute respiratory syndrome; MERS: Middle east respiratory syndrome; GGO: Ground-glass opacity.

\section{Declarations}

\section{Availability of data and materials}

All data generated or analyzed during this study are included in this published article.

\section{Ethics approval and consent to participate}

Ethics Committee of Wuhan Union Hospital of Huazhong University of Science and Technology approved this study.

\section{Consent for publication}

Oral consent to publish was obtained from all patients in this study.

\section{Competing interests}

All authors have read and approved the content, and declare no conflicts of

\section{Funding}

Not applicable.

\section{Authors' contributions}

MD and XML carried out the data curation, Conceptualization, Original draft preparation, Writing. Yu Zhang: Conceptualization, Methodology, Reviewing and Supervision. XQZ and TJL contributed to the data curation, Investigation. CHX and FY participated in the data curation, Investigation. YZ and LY help to draft the manuscript and revised the final version of the manuscript. All authors read and approved the final manuscript.

\section{Acknowledgements}

Not applicable.

\section{References}


1. Li Q, Guan X, Wu P, Wang X, Zhou L, Tong Y, Ren R, Leung KSM, Lau EHY, Wong JY, Xing X, Xiang N, Wu Y, Li C, Chen Q, Li D, Liu T, Zhao J, Liu M, Tu W, Chen C, Jin L, Yang R, Wang Q, Zhou S, Wang R, Liu H, Luo Y, Liu Y, Shao G, Li H, Tao Z, Yang Y, Deng Z, Liu B, Ma Z, Zhang Y, Shi G, Lam TTY, Wu JT, Gao GF, Cowling BJ, Yang B, Leung GM, Feng Z. Early Transmission Dynamics in Wuhan, China, of Novel Coronavirus-Infected Pneumonia. N Engl J Med. 2020;382(13):1199-207. doi:10.1056/NEJMoa2001316.

2. Zhu N, Zhang D, Wang W, Li X, Yang B, Song J, Zhao X, Huang B, Shi W, Lu R, Niu P, Zhan F, Ma X, Wang D, Xu W, Wu G, Gao GF, Tan W. China Novel Coronavirus I, Research T. A Novel Coronavirus from Patients with Pneumonia in China, 2019. N Engl J Med. 2020;382(8):727-33. doi:10.1056/NEJMoa2001017.

3. Huang C, Wang Y, Li X, Ren L, Zhao J, Hu Y, Zhang L, Fan G, Xu J, Gu X, Cheng Z, Yu T, Xia J, Wei Y, Wu W, Xie X, Yin W, Li H, Liu M, Xiao Y, Gao H, Guo L, Xie J, Wang G, Jiang R, Gao Z, Jin Q, Wang J, Cao B. Clinical features of patients infected with 2019 novel coronavirus in Wuhan, China. The Lancet. 2020;395(10223):497-506. doi:10.1016/s0140-6736(20)30183-5.

4. Chen N, Zhou M, Dong X, Qu J, Gong F, Han Y, Qiu Y, Wang J, Liu Y, Wei Y, Xia Ja, Yu T, Zhang X, Zhang L. Epidemiological and clinical characteristics of 99 cases of 2019 novel coronavirus pneumonia in Wuhan, China: a descriptive study. The Lancet. 2020;395(10223):507-13. doi:10.1016/s0140-6736(20)30211-7.

5. Wu F, Zhao S, Yu B, Chen Y-M, Wang W, Song Z-G, Hu Y, Tao Z-W, Tian J-H, Pei Y-Y, Yuan M-L, Zhang Y-L, Dai F-H, Liu Y, Wang Q-M, Zheng J-J, Xu L, Holmes EC, Zhang Y-Z. A new coronavirus associated with human respiratory disease in China. Nature. 2020;579(7798):265-9. doi:10.1038/s41586-020-2008-3.

6. Zhou P, Yang XL, Wang XG, Hu B, Zhang L, Zhang W, Si HR, Zhu Y, Li B, Huang CL, Chen HD, Chen J, Luo Y, Guo H, Jiang RD, Liu MQ, Chen Y, Shen XR, Wang X, Zheng XS, Zhao K, Chen QJ, Deng F, Liu LL, Yan B, Zhan FX, Wang YY, Xiao GF, Shi ZL. A pneumonia outbreak associated with a new coronavirus of probable bat origin. Nature. 2020;579(7798):270-3. doi:10.1038/s41586-020-2012-7.

7. World Health Organization. Coronavirus Disease 2019 (COVID-19) Situation Reports - 47. https://www.who.int/emergencies/diseases/novelcoronavirus-2019/situation-reports. Published July 14, 2020. Accessed July 14, 2020.

8. https://.

9. Yin Y, Wunderink RG. MERS, SARS and other coronaviruses as causes of pneumonia. Respirology. 2018;23(2):130-7. doi:10.1111/resp.13196.

10. Zaki AM, van Boheemen S, Bestebroer TM, Osterhaus ADME, Fouchier RAM. Isolation of a Novel Coronavirus from a Man with Pneumonia in Saudi Arabia. N Engl J Med. 2012;367(19):1814-20. doi:10.1056/NEJMoa1211721.

11. Pan F, Ye T, Sun P, Gui S, Liang B, Li L, Zheng D, Wang J, Hesketh RL, Yang L, Zheng C. Time Course of Lung Changes On Chest CT During Recovery From 2019 Novel Coronavirus (COVID-19) Pneumonia. Radiology 2020:200370. doi:10.1148/radiol.2020200370.

12. Wang Y, Dong C, Hu Y, Li C, Ren Q, Zhang X, Shi H, Zhou M. Temporal Changes of CT Findings in 90 Patients with COVID-19 Pneumonia: A Longitudinal Study. Radiology 2020:200843. doi: 10.1148/radiol.2020200843.

13. Bernheim A, Mei X, Huang M, Yang Y, Fayad ZA, Zhang N, Diao K, Lin B, Zhu X, Li K, Li S, Shan H, Jacobi A, Chung M. Chest CT Findings in Coronavirus Disease-19 (COVID-19): Relationship to Duration of Infection. Radiology 2020:200463. doi: 10.1148/radiol.2020200463.

14. Chung M, Bernheim A, Mei X, Zhang N, Huang M, Zeng X, Cui J, Xu W, Yang Y, Fayad ZA, Jacobi A, Li K, Li S, Shan H. CT Imaging Features of 2019 Novel Coronavirus (2019-nCoV). Radiology. 2020;295(1):202-7. doi:10.1148/radiol.2020200230.

15. Pan Y, Guan H. Imaging changes in patients with 2019-nCov. European radiology 2020. doi: 10.1007/s00330-020-06713-Z.

16. Shi H, Han X, Jiang N, Cao Y, Alwalid O, Gu J, Fan Y, Zheng C. Radiological findings from 81 patients with COVID-19 pneumonia in Wuhan, China: a descriptive study. The Lancet Infectious diseases. 2020. doi:10.1016/S1473-3099(20)30086-4.

17. Xie X, Zhong Z, Zhao W, Zheng C, Wang F, Liu J. Chest CT for Typical 2019-nCoV Pneumonia: Relationship to Negative RT-PCR Testing. Radiology 2020:200343. doi: 10.1148/radiol.2020200343.

18. Fang Y, Zhang H, Xie J, Lin M, Ying L, Pang P, Ji W. Sensitivity of Chest CT for COVID-19: Comparison to RT-PCR. Radiology 2020:200432. doi:10.1148/radiol.2020200432.

19. Huang P, Liu T, Huang L, Liu H, Lei M, Xu W, Hu X, Chen J, Liu B. Use of Chest CT in Combination with Negative RT-PCR Assay for the 2019 Novel Coronavirus but High Clinical Suspicion. Radiology. 2020;295(1):22-3. doi:10.1148/radiol.2020200330.

20. Zhao W, Zhong Z, Xie X, Yu Q, Liu J. Relation Between Chest CT Findings and Clinical Conditions of Coronavirus Disease (COVID-19) Pneumonia: A Multicenter Study. AJR American journal of roentgenology 2020:1-6. doi: 10.2214/AJR.20.22976.

21. Xu YH, Dong JH, An WM, Lv XY, Yin XP, Zhang JZ, Dong L, Ma X, Zhang HJ, Gao BL. Clinical and computed tomographic imaging features of novel coronavirus pneumonia caused by SARS-CoV-2. J Infect. 2020;80(4):394-400. doi:10.1016/j.jinf.2020.02.017.

22. Russell AS, Crowther S. Tennis leg-a new variant of an old syndrome. Clin Rheumatol. 2011;30(6):855-7. doi:10.1007/s10067-011-1681-x.

23. Ooi GC, Khong PL, Müller NL, Yiu WC, Zhou LJ, Ho JCM, Lam B, Nicolaou S, Tsang KWT. Severe Acute Respiratory Syndrome: Temporal Lung Changes at Thin-Section CT in 30 Patients. Radiology. 2004;230(3):836-44. doi:10.1148/radiol.2303030853.

24. Austin JH, Müller NL, Friedman PJ, Hansell DM, Naidich DP, Remy-Jardin M, Webb WR, Zerhouni EA. Glossary of terms for CT of the lungs: recommendations of the Nomenclature Committee of the Fleischner Society. Radiology. 1996;200(2):327-31.

doi:10.1148/radiology.200.2.8685321. 
25. Franquet T. Imaging of Pulmonary Viral Pneumonia. Radiology. 2011;260(1):18-39. doi:10.1148/radiol.11092149.

26. Hansell DM, Bankier AA, MacMahon H, McLoud TC, Müller NL, Remy J. Fleischner Society: Glossary of Terms for Thoracic Imaging $\backslash r<$ sup > 1. Radiology 2008;246(3):697-722.

27. Chang Y-C, Yu C-J, Chang S-C, Galvin JR, Liu H-M, Hsiao C-H, Kuo P-H, Chen K-Y, Franks TJ, Huang K-M, Yang P-C. Pulmonary Sequelae in Convalescent Patients after Severe Acute Respiratory Syndrome: Evaluation with Thin-Section CT. Radiology. 2005;236(3):1067-1075. doi: 10.1148/radiol.2363040958.

28. Remy-Jardin M, Giraud F, Remy J, Copin MC, Gosselin B, Duhamel A. Importance of ground-glass attenuation in chronic diffuse infiltrative lung disease: pathologic-CT correlation. Radiology. 1993;189(3):693-8. doi:10.1148/radiology.189.3.8234692.

29. Antonio GE, Wong KT, Hui DSC, Wu A, Lee N, Yuen EHY, Leung CB, Rainer TH, Cameron P, Chung SSC, Sung JJY, Ahuja AT. Thin-Section CT in Patients with Severe Acute Respiratory Syndrome Following Hospital Discharge: Preliminary Experience. Radiology. 2003;228(3):810-5. doi:10.1148/radiol.2283030726.

30. Antonio GE, Ooi CGC, Wong KT, Tsui ELH, Wong JSW, Sy ANL, Hui JYH, Chan CY, Huang HYH, Chan YF, Wong TP, Leong LLY, Chan JCK, Ahuja AT. Radiographic-Clinical Correlation in Severe Acute Respiratory Syndrome: Study of 1373 Patients in Hong Kong. Radiology. 2005;237(3):1081-90. doi:10.1148/radiol.2373041919.

31. Das KM, Lee EY, Enani MA, AlJawder SE, Singh R, Bashir S, Al-Nakshbandi N, AIDossari K, Larsson SG. CT Correlation With Outcomes in 15 Patients With Acute Middle East Respiratory Syndrome Coronavirus. Ajr American Journal of Roentgenology;204(4):736-742.

32. Ajlan AM, Ahyad RA, Jamjoom LG, Alharthy A, Madani TA. Middle East respiratory syndrome coronavirus (MERS-CoV) infection: chest CT findings. AJR American journal of roentgenology. 2014;203(4):782-7. doi:10.2214/AJR.14.13021.

\section{Figures}
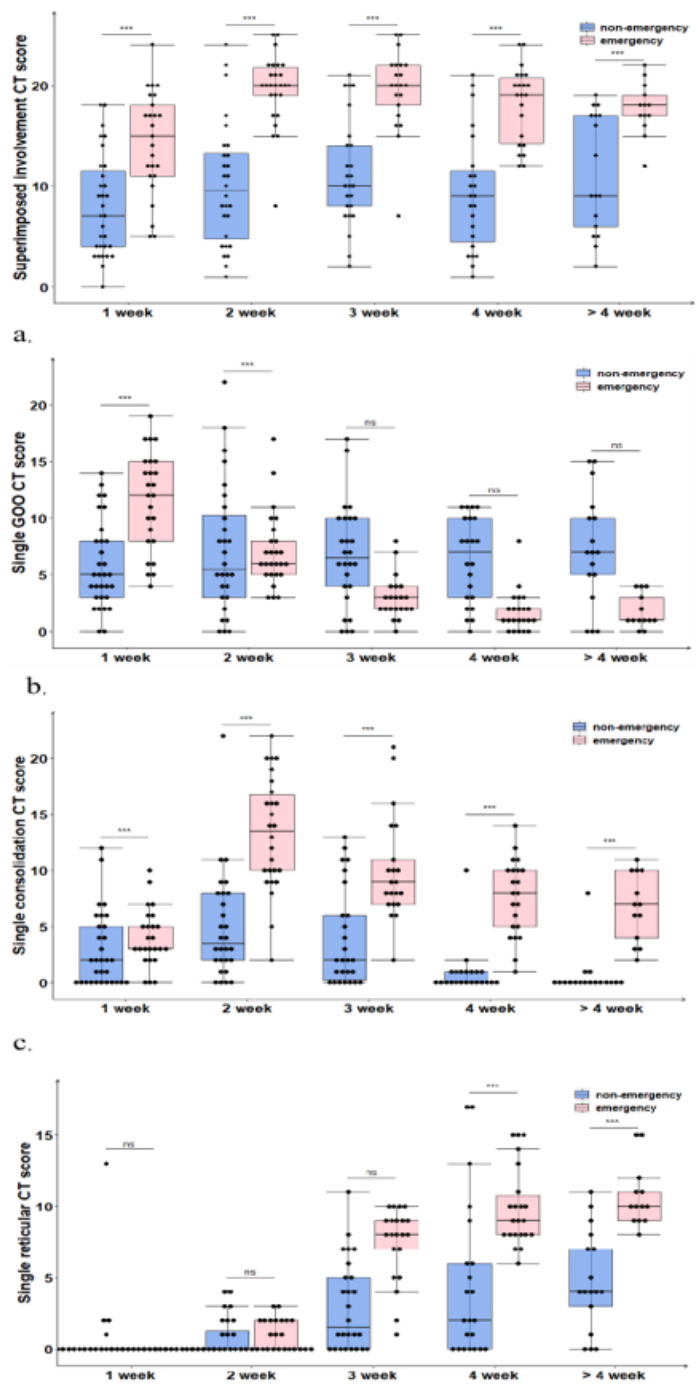

d.

Figure 1 
(a) Temporal change of median values of superimposed involvement CT score, non-emergency and emergency both peaked in 2nd week, emergency was significantly higher than non-emergency(Pख0.000); (b) Temporal change of median values of single GGO CT score, emergency showed a downward trend(Pख0.000); (c) Temporal change of median values of single consolidation CT score, non-emergency and emergency both peaked in 2nd week, emergency was significantly higher than non-emergency(Pख0.000); (d) Temporal change of median values of single reticular CT score, non-emergency and emergency both peaked after 4 weeks, emergency (Pख0.000) and non-emergency(P凶0.000) showed a upward trend.

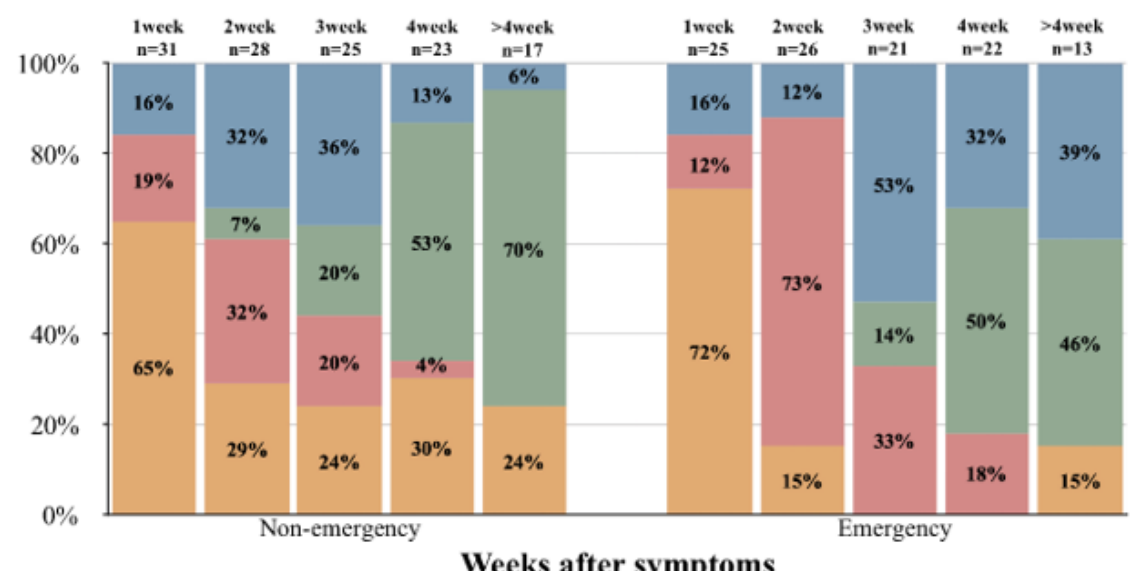

a. Ground-glass opacities pattern Consolidation pattern $\quad$ Reticular pattem

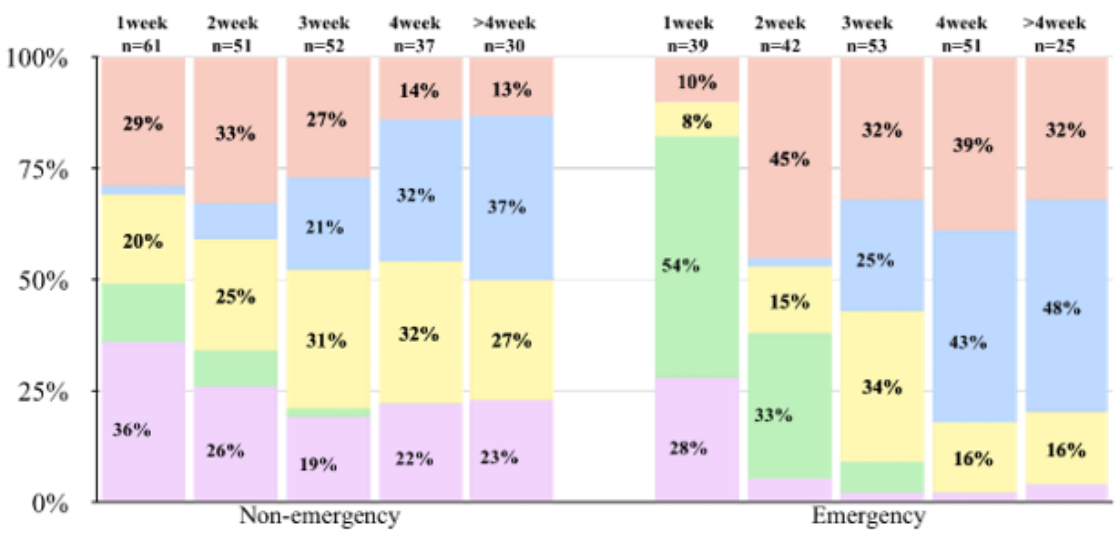

Weeks after symptoms

b.

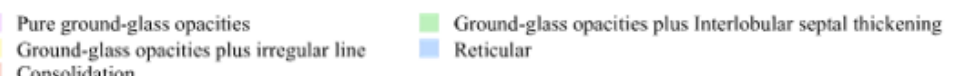

Figure 2

(a) Stacked-bar graph shows temporal change of the predominantly CT patterns on non-emergency and emergency group at various time points from onset of symptoms. (b) Stacked-bar graph shows number of positive CT feature on non-emergency and emergency group at various time points from onset of symptoms. 


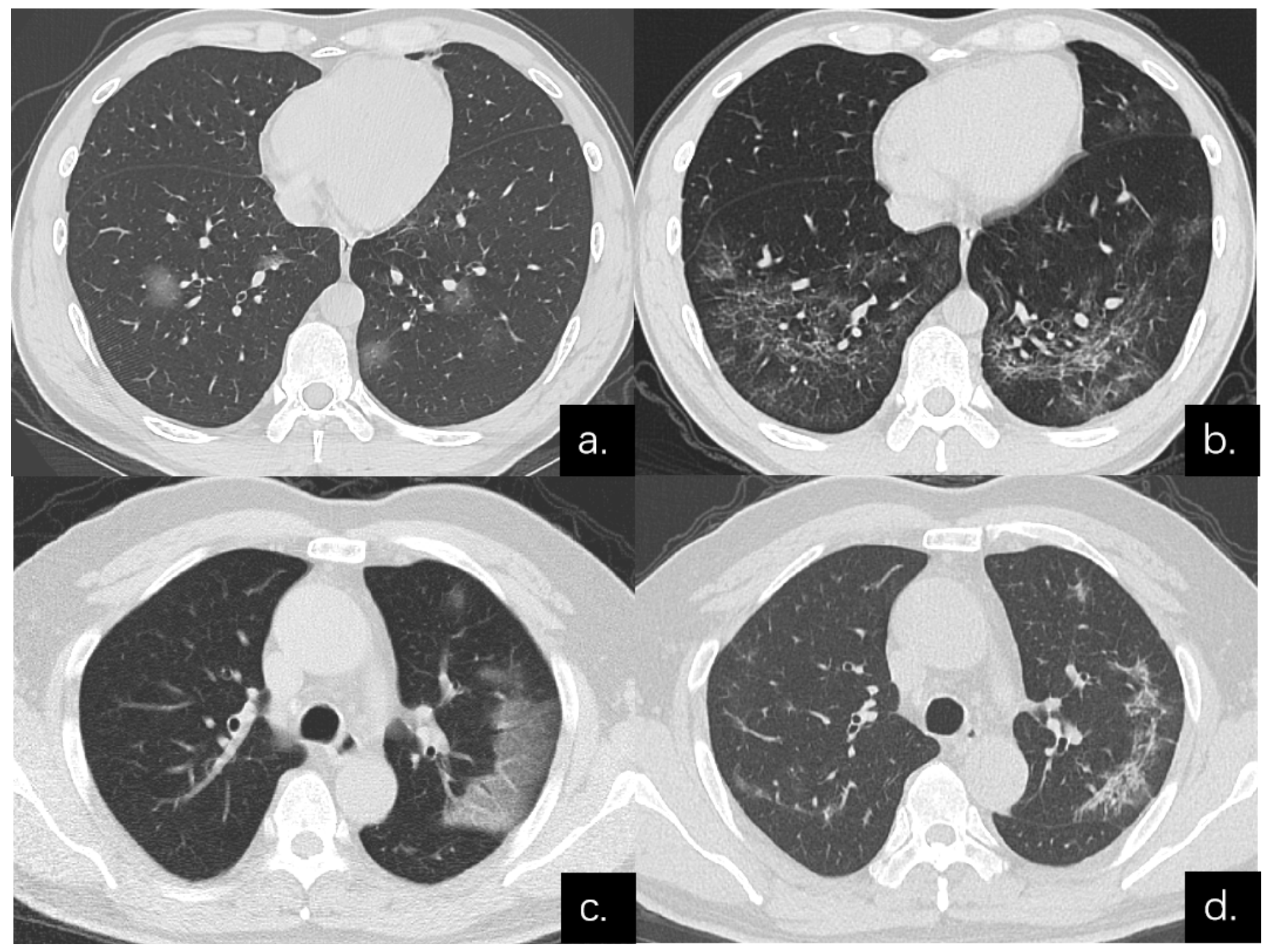

Figure 3

Series CT scans from non-emergency group in 38-year-old man with COVID-19 pneumonia. (a) Scan obtained on illness days 6 showed a predominantly GGO pattern with multiple pure GGO in lower lobes. (b) Scan obtained on illness days 31 showed a predominantly reticular pattern with interlacing line shadows that suggest a mesh mainly in lower lobes. Series CT scans from non-emergency group in 54-year-old man with COVID-19 pneumonia. (c) Scan obtained on illness days 1 showed GGO in left upper lobe. Predominantly GGO pattern. (d) Scan obtained on illness day 27 showed a predominantly reticular pattern with interlacing line shadows mainly in left upper lobe. 


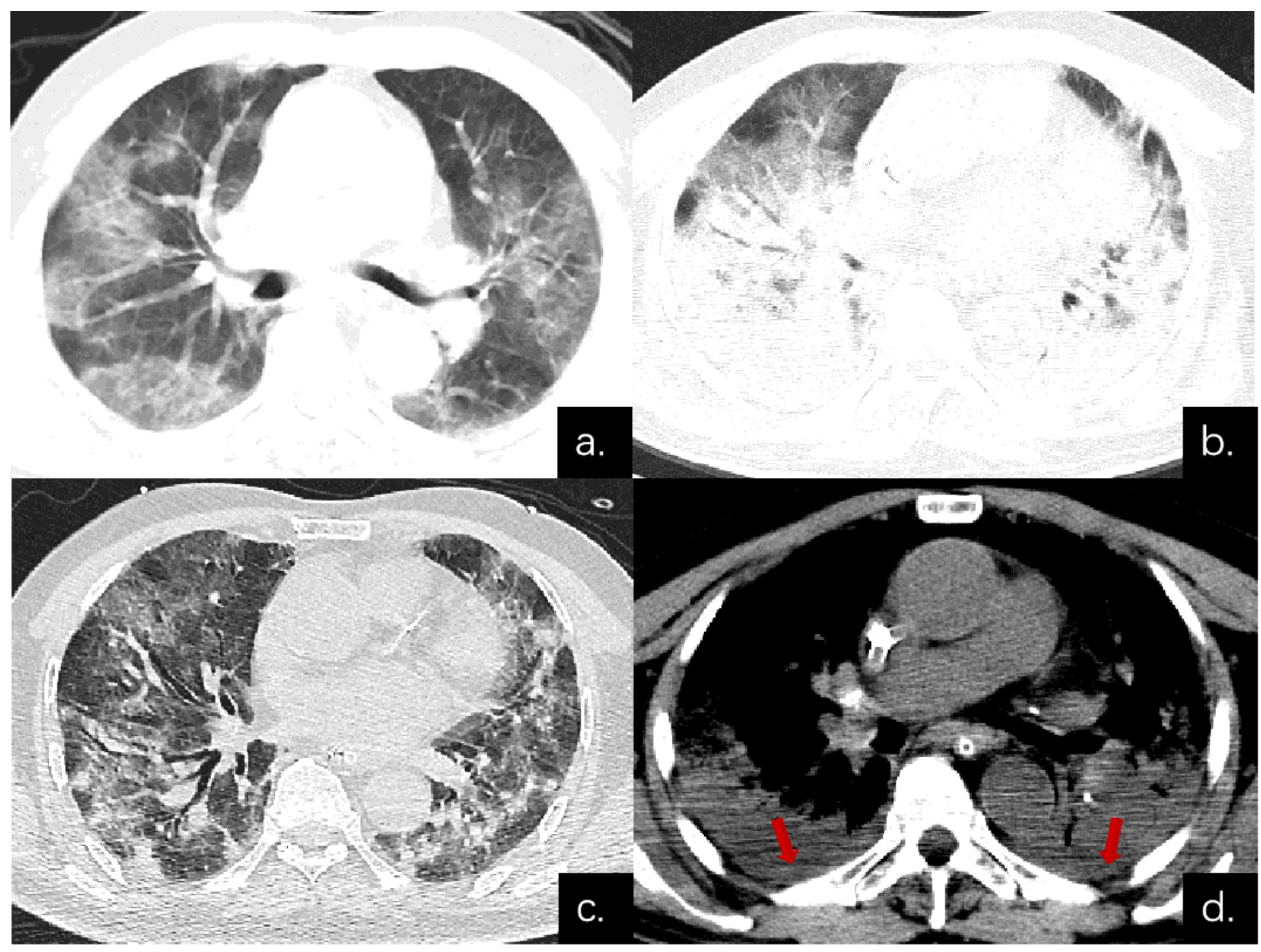

Figure 4

Series CT scans from emergency group in 85-year-old man with COVID-19 pneumonia. (a) Scan obtained on illness days 4, showing the patchy Ground-glass opacities plus Interlobular septal thickening (crazy paving). Predominantly CT pattern is GGO pattern, 12 for superimposed involvement CT score; (b, d) Scan obtained on illness days 10, disease progresses rapidly to ARDS, PaO2 / FiO2 continued to decrease with a minimum of 85 , and patient has been treated with ECMO. figure $b$ is lung window, diffuse distribution of consolidation and bronchial meteorology can be seen in both lungs, mainly dorsal, while crazy paving also can be seen on the ventral side. figure $d$ is the soft tissue window, and pleural effusion can be found under the dorsal pleura (red arrows). Predominantly CT pattern is consolidation pattern, 25 for superimposed involvement CT score; (c) Scan obtained on illness days 40, the lung lesions were further absorbed and the reticular was increased, accompanied with fibrotic changes. Predominantly CT pattern was reticular pattern, 17 for superimposed involvement CT score. 